Louisiana State University

LSU Digital Commons

Faculty Publications

Department of Geology and Geophysics

3-21-2019

\title{
Chemical Durability and Dissolution Kinetics of lodoapatite in Aqueous Solutions
}

\author{
Zelong Zhang \\ Louisiana State University \\ William L. Ebert \\ Argonne National Laboratory \\ Tiankai Yao \\ Rensselaer Polytechnic Institute \\ Jie Lian \\ Rensselaer Polytechnic Institute \\ Kalliat T. Valsaraj \\ Cain Department of Chemical Engineering
}

See next page for additional authors

Follow this and additional works at: https://digitalcommons.Isu.edu/geo_pubs

\section{Recommended Citation}

Zhang, Z., Ebert, W., Yao, T., Lian, J., Valsaraj, K., \& Wang, J. (2019). Chemical Durability and Dissolution Kinetics of lodoapatite in Aqueous Solutions. ACS Earth and Space Chemistry, 3 (3), 452-462.

https://doi.org/10.1021/acsearthspacechem.8b00162

This Article is brought to you for free and open access by the Department of Geology and Geophysics at LSU Digital Commons. It has been accepted for inclusion in Faculty Publications by an authorized administrator of LSU Digital Commons. For more information, please contact ir@lsu.edu. 


\section{Authors}

Zelong Zhang, William L. Ebert, Tiankai Yao, Jie Lian, Kalliat T. Valsaraj, and Jianwei Wang 


\title{
- Chemical Durability and Dissolution Kinetics of lodoapatite in Aqueous Solutions
}

\author{
3 Zelong Zhang, ${ }^{\dagger}$ William L. Ebert, ${ }^{\S}$ Tiankai Yao," Jie Lian," Kalliat T. Valsaraj," and Jianwei Wang, ${ }^{\ddagger}$ \\ $4{ }^{\dagger}$ Department of Geology and Geophysics, Center for Computation and Technology, Louisiana State University, Baton Rouge, \\ 5 Louisiana 70803, United States \\ ${ }_{6}{ }^{\S}$ Chemical and Fuel Cycle Technologies Division, Argonne National Lab, Argonne, Illinois 60439, United States \\ 7 "Department of Mechanical, Aerospace, and Nuclear Engineering, Rensselaer Polytechnic Institute, Troy, New York 12180, United \\ 8 States \\ $9{ }^{\ddagger}$ Cain Department of Chemical Engineering, Louisiana State University, Baton Rouge, Louisiana 70803, United States

11 ABSTRACT: Understanding the long-term release of radionuclides 12 from nuclear waste to the environment is critical for public acceptance 13 and sustainability of nuclear energy. Iodoapatite, a synthetic material 14 similar to mineral vanadinite proposed for radioactive iodine-129 15 immobilization, is employed in this study as a model system for iodine 16 waste forms and ceramic waste forms in general to understand its long17 term chemical durability. Semidynamic leaching experiments were 18 performed in cap-sealed Teflon vessels to evaluate the chemical 19 durability at temperatures from 20 to $90{ }^{\circ} \mathrm{C}$ and $\mathrm{pH}$ values from 4 to 209 using deionized water and $\mathrm{pH}$ buffer solutions. The leachates were 21 analyzed using inductively coupled plasma-mass spectrometry. The

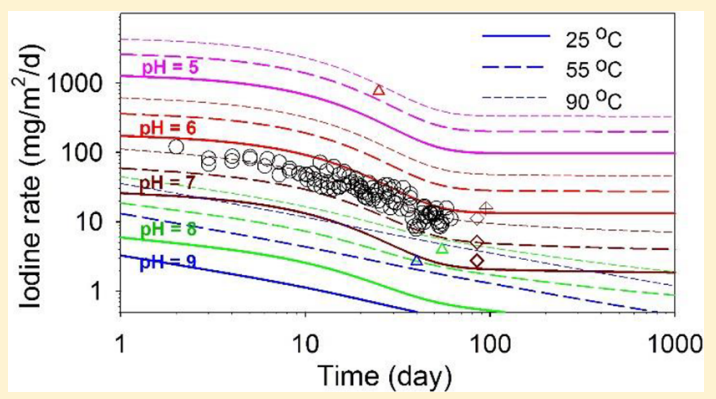
leached surfaces were examined by X-ray diffraction, scanning electron microscopy, and Raman spectroscopy. Effects of test variables including surface-to-volume ratio, leachant replacement interval, and environmental variables including temperature and $\mathrm{pH}$ on the dissolution rate were systematically investigated. The activation energy of the dissolution was $16.9 \pm 1.5 \mathrm{~kJ} / \mathrm{mol}$ for the matrix elements and $34.4 \pm 3.9 \mathrm{~kJ} / \mathrm{mol}$ for the diffusive iodine release. The order of the $\mathrm{pH}$ effect on the dissolution rate as a power law exponent was $0.87 \pm 0.08$. The effect of the surface-to-volume ratio and replacement interval was approximated by a single exponential function rise to maximum. Fully parametrized models were then combined to predict iodine release rate under various conditions. The result suggests that the long-term iodine release is controlled by iodide diffusion when the matrix dissolution rate is very low in near neutral $\mathrm{pH}$ solutions and by matrix dissolution when the dissolution rate is high at low $\mathrm{pH}$. The present study demonstrates a mechanistic approach to parametrize models that can be used to evaluate the performance of nuclear waste forms under various disposal environments.

KEYWORDS: apatite, iodine, radionuclides, fission product, waste form, activation energy, saturation effect, waste disposal

34 Sustained development of nuclear energy requires safe disposal 35 of radionuclides produced from nuclear fission. Many of these 36 fission products are short-lived, and those with great concerns 37 include technetium-99, cesium-135, and iodine-129. ${ }^{1-6}$ There 38 are 37 known iodine isotopes, all of which are radioactive 39 except iodine-127. Nuclear fission produces at least three 40 radioactive isotopes: iodine-129, 131 , and 132 . The latter two 41 are short-lived with a half-life of about 8 days and $2 \mathrm{~h}$, 42 respectively. Iodine-129 $(\sim 15.7$ million years half-life, $\sim 0.8 \%$ 43 yield) is particularly important because of its long half-life and 44 weak interactions with the engineering barriers and near field 45 rocks of geological formations in disposal environment; as a 46 result, iodine- 129 is a primary dose contributor to the 47 environment considered in disposal safety analyses. ${ }^{7}$ Once 48 released from the waste form, the iodine is expected to remain 49 stable in the form of iodide $\left(\mathrm{I}^{-}\right)$, which occupies a large area of the Eh-pH stability field in the aqueous environment. ${ }^{8,9}$ Its low 50 ionic potential (charge to radius ratio) makes iodide less likely 51 to form insoluble compounds by interactions with the rocks 52 and dissolved species in the environment. In addition, surfaces 53 of silicate minerals, common in disposal environments, are 54 often negatively charged because their point of zero charge is 55 usually lower than the $\mathrm{pH}$ values of ground waters expected to 56 occur in the near field and geological formations, leading to 57 negligible iodide adsorption on those materials. Under 58 oxidizing conditions, iodide may get oxidized to $\mathrm{I}_{2}$ at acidic 59 and iodate $\left(\mathrm{IO}_{3}{ }^{-}\right)$at neutral to basic conditions. Both these 60 species are expected to be mobile. Therefore, the immobiliza- 61

Received: October 22, 2018

Revised: February 4, 2019

Accepted: February 19, 2019

Published: February 19, 2019 
62 tion of iodine (including I-129) has remained a topic of 63 ongoing research and development interest. ${ }^{10-20}$

64 Iodine waste forms can be classified into two categories 65 based on immobilization mechanism: incorporation and 66 encapsulation. In incorporation, iodine (e.g., iodide, iodate) 67 is immobilized in a chemical coordination environment, which 68 can be a crystalline phase where iodine occupies the 69 crystallographic sites (e.g., iodoapatite, iodosodalite) or a 70 glass where iodine is dissolved. The incorporation can be 71 stoichiometric if iodine is the sole species fully occupying a 72 crystallographic site or nonstoichiometric if a variable fraction 73 of the crystallographic site is occupied. The amount 74 incorporated often depends on iodine solubility in the material. 75 For borosilicate glass used for high level nuclear waste, the 76 solubility of iodine is very low largely because of the volatility 77 of iodine at vitrification temperatures and structural incom78 patibility in borosilicate glass. ${ }^{21}$ Small to trace amount of 79 iodine can always be incorporated in a variety of materials 80 mostly due to the entropic contribution to the free energy of 81 the incorporation. However, iodine loading in a material needs 82 to be sufficiently large to be cost-effective for an acceptable 83 waste form. In encapsulation, iodine is retained in a phase (e.g., $84 \mathrm{AgI}$ ) different from its host matrix such as low-temperature 85 glass. ${ }^{15}$ The matrix provides a mechanical and chemical barrier 86 to contain the iodine phase. A number of waste forms have 87 been considered for iodine-129 with varying amount of iodine 88 loading capacities, ${ }^{20}$ including borosilicate glass for high-level 89 waste, low-temperature glasses, ${ }^{15,22-25}$ and crystalline 90 phases $^{17,26-30}$ such as iodosodalite ${ }^{26,27}$ and apatites. ${ }^{13,19,31-38}$ 91 Many of the iodine waste forms developed in the literature 92 provide promising properties for iodine immobilization by 93 either incorporation or encapsulation. ${ }^{20}$ However, the level of 94 difficulty in evaluation of their long-term durability in the 95 environment varies significantly, which is a great challenge for 96 those encapsulated multiphase waste forms due to their phase 97 and microstructure complexities. In comparison, the durability 98 of single phase crystalline iodine waste forms can be more 99 easily evaluated because of their well-defined crystal structure 100 and crystallographic sites of the interested elements, simpler 101 microstructure, and relative ease of test results interpretation. 102 Among the single phase crystalline waste forms, apatite has a 103 number of advantageous properties including long-term 104 durability, ${ }^{39,40}$ structural and chemical flexibility, ${ }^{41-43}$ and 105 tolerance against the aging effect of radionuclides due to 106 radioparagenesis. ${ }^{44-46}$

107 A number of iodoapatite compositions have been synthe108 sized, and their physical properties have been characterized for 109 immobilization of iodine-129. . $^{13,19,31-38,47-49} \mathrm{~Pb}-\mathrm{V}$ iodoapa110 tite $\left(\mathrm{Pb}_{5}\left(\mathrm{VO}_{4}\right)_{3} \mathrm{I}\right)$, inspired by mineral vanadinite $111\left(\mathrm{~Pb}_{5}\left(\mathrm{VO}_{4}\right)_{3} \mathrm{Cl}\right)$, can be readily synthesized to dense monolith 112 pellets, which are suitable for durability test. ${ }^{38,40}$ Static, 113 semidynamic, and flow-through leaching experiments have 114 been carried out to quantify the chemical durability of 115 iodoapatite in deionized water in order to evaluate its 116 performance in the aqueous environment. ${ }^{40,47,48,50-52}$ The 117 results from these experiments consistently point to a chemical 118 durability that is comparable to or better than nuclear glass, ${ }^{48}$ 119 using different leaching methods and samples with different 120 compositions. For instance, a rate of $2.5 \times 10^{-3} \mathrm{~g} / \mathrm{m}^{2} / \mathrm{d}$ was 121 reported after 2 weeks using a flow-through method at $90{ }^{\circ} \mathrm{C}$ 122 for an iodoapatite $\left(\mathrm{Pb}_{10}\left(\mathrm{VO}_{4}\right)_{4.8}\left(\mathrm{PO}_{4}\right)_{1.2} \mathrm{I}_{2}\right){ }^{50}$ In a recent 123 leaching experiment of iodoapatite $\mathrm{Pb}_{10}\left(\mathrm{VO}_{4}\right)_{6} \mathrm{I}_{2}$, a rate of 2.3 $124 \times 10^{-3} \mathrm{~g} / \mathrm{m}^{2} / \mathrm{d}$ was reached after 21 days of experiment using a semidynamic leaching method at $90{ }^{\circ} \mathrm{C} .{ }^{40}$ In a static leaching 125 experiment at $50{ }^{\circ} \mathrm{C}$, an initial release rate of iodine $2 \times 10^{-2}{ }_{126}$ $\mathrm{g} / \mathrm{m}^{2} / \mathrm{d}$ and a residual rate of $7 \times 10^{-5} \mathrm{~g} / \mathrm{m}^{2} / \mathrm{d}$ with a $S / V$ ratio 127 of 800 and $8000 \mathrm{~m}^{-1}$, respectively, were reported for 128 iodoapatite $\mathrm{Ca}_{10}\left(\mathrm{PO}_{4}\right)_{6}\left(\mathrm{IO}_{3}\right)_{0.92}(\mathrm{OH})_{1.08} \cdot{ }^{19,48}$ Although these 129 reported rates vary largely due to differences in sample 130 compositions, test methods, test parameters, sample synthesis 131 methods, and how the rate was reported, iodoapatite was 132 found to be chemically durable, comparable to or better than 133 nuclear glass residual rate $\left(1.1 \times 10^{-2}\right.$ to $1 \times 10^{-4} \mathrm{~g} / \mathrm{m}^{2} / 134$ d). ${ }^{48,53}$ Due to the large difference in terms of iodine loading 135 $(\sim 8-20$ wt $\%$ iodine in iodoapatites and $\sim 1$ wt $\%$ in 136 borosilicate glass ${ }^{21,54}$ ), the ceramic waste form incorporates 137 about ten times more iodine than nuclear glass with at least a 138 comparable release rate. In order to understand the iodine 139 release mechanism from iodoapatite, a semidynamic test 140 method was used to distinguish between dissolution-controlled 141 and diffusion-controlled release processes. ${ }^{40}$ Elemental anal- 142 ysis, X-ray diffraction, and IR spectroscopic results suggest that 143 the iodide release is initially dominated by ion exchange of 144 iodide $\left(\mathrm{I}^{-}\right)$with hydroxide $\left(\mathrm{OH}^{-}\right)$in solution, while lead and 145 vanadium are released via constant dissolution. ${ }^{40}$ Such a 146 release mechanism has also been considered previously to 147 explain incongruent dissolution, time-dependent release rate of 148 iodine, and the $\mathrm{pH}$ evolution using flow-through and static 149 leaching experiments. ${ }^{48,50,52}$

In order to predict the long-term release behavior of iodine 151 from iodoapatite, experiments designed to probe a range of 152 environmental conditions are needed to fully understand the 153 dissolution behavior. In addition to $\mathrm{pH}$ and temperature, the 154 dissolution rate is also affected by the saturation condition of 155 the aqueous solution. For instance, in a scenario where water is 156 limited, the concentration of the dissolved species is high, and 157 the chemical affinity and dissolution rate decrease quickly and 158 become diminished when the solution is at equilibrium. 159 However, when water is abundant, similar to experiments at 160 far-from-equilibrium conditions, the concentration of relevant 161 species in the solution is low, the free energy driving force for 162 the dissolution is large, and the dissolution rate is high and 163 approximately a constant. The saturation conditions can be 164 mimicked using a semidynamic leaching experiment by 165 changing surface to volume ratio and leachant replacement 166 interval. $^{55}$

The present study uses iodoapatite, a synthetic material as a 168 model system for iodine waste forms and ceramic waste forms 169 in general, to understand its long-term chemical durability. The 170 experiments were designed to extend the previous leaching 171 tests ${ }^{40}$ to longer time scales when the short-term dissolution 172 rate components diminish, and to systematically evaluate the 173 effects of test and environmental variables on the dissolution 174 including saturation state (i.e., $S / V$, interval), temperature, and 175 $\mathrm{pH}$. The goal is to understand the kinetics of leaching behavior 176 under certain sets of conditions to contribute toward 177 establishing iodoapatite as a feasible iodine waste form, by 178 parametrizing mechanistic models that consider all critical 179 processes and a range of test and environmental conditions for 180 the prediction of iodine release. Such a mechanistic approach, 181 generally applicable to other nuclear waste forms, could be 182 used to predict the dissolution rate under various environ- 183 mental conditions and to evaluate the durability of the 184 iodoapatite at longer time scales than examined. 


\section{EXPERIMENTAL METHODS}

187 Sample and Materials Characterization. Three pellets 188 of iodoapatite samples up to $14 \mathrm{~mm}$ in diameter and $3 \mathrm{~mm}$ in 189 thickness with a composition of $\mathrm{Pb}_{9.85}\left(\mathrm{VO}_{4}\right)_{6} \mathrm{I}_{1.7}$ and $\sim 96 \%$ 190 theoretical density were used in the leaching experiments
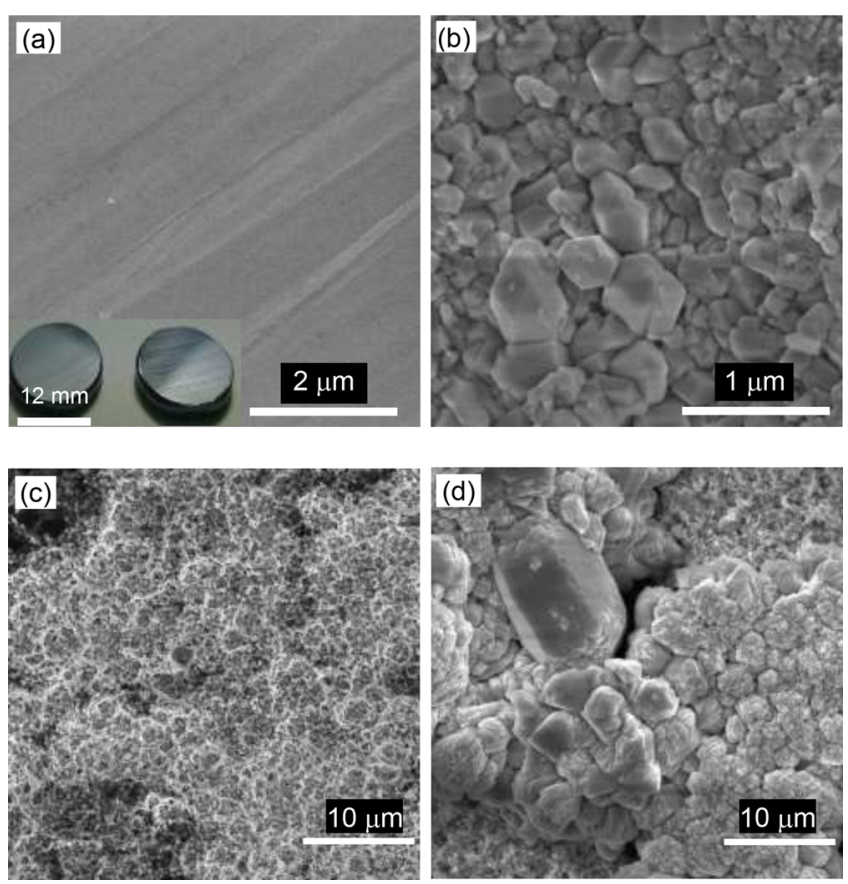

Figure 1. Optical and SEM images of the pellets and surfaces of the iodoapatite samples from leaching experiments. (a) Fresh polished surface of an iodoapatite pellet. Inset: pellets of apatite synthesized using high energy ball milling and sparkling plasma sintering. (b) Surface of a leached pellet of apatite after 3 weeks of test with DI water at $90{ }^{\circ} \mathrm{C}$. (c) Surface of a leached pellet using a $\mathrm{pH} 6$ buffering solution for 2 weeks. (d) Surface of a leached pellet using $\mathrm{pH} 4$ buffering solution for 2 weeks. Majority of the surface is covered by the secondary phase chervetite precipitates.

192 of the samples are summarized here and were reported in 193 separate publications. ${ }^{38,40}$ Iodoapatite was synthesized using 194 high energy ball milling (HEBM) and spark plasma sintering 195 (SPS) techniques. The slightly under-stoichiometry of the 196 composition with respect to $\mathrm{Pb}_{10}\left(\mathrm{VO}_{4}\right)_{6} \mathrm{I}_{2}$ is a result of loss of 197 some of the iodine during the synthesis. Impurities such as $198 \mathrm{PbI}_{2}$ and $\mathrm{Pb}_{3}\left(\mathrm{VO}_{4}\right)_{2}$ from incomplete reaction are negligible as 199 determined by X-ray diffraction. Graphite peaks sometimes 200 may appear in X-ray diffraction as a result of a residual from 201 the sample chamber material during SPS synthesis, which is 202 inert to dissolution reactions in this study. Samples were 203 mechanically polished with ethanol lubrication and were 204 thoroughly rinsed using ethanol and air-dried before leaching 205 experiments. Samples were reused after each leaching test. Due 206 to the time dependence of iodine release, for the experiments 207 at different $\mathrm{pH}$ values and temperatures, a pellet was cut to a 208 number of pieces with approximately the same size to provide 209 consistent $\mathrm{pH}$ - and temperature-dependent results. Before and 210 after a leaching experiment, sample surfaces were characterized 211 by X-ray diffraction (XRD), scanning electron microscopy 212 (SEM), and Raman spectroscopy on the surfaces of the pellets 213 (Figure 1). The leachate was analyzed with an inductively 214 coupled plasma-mass spectrometry (ICP-MS) system with an uncertainty of less than $10 \%$. Based on measurements from 215 different batches of experiments, the overall error of the 216 measured concentration is estimated to be $\sim 20 \%$, which is 217 propagated from ICP-MS analysis, dilution of the leachate 218 before analysis, geometric surface area estimation, leachant 219 weight loss during experiment, and oven temperature control 220 homogeneity, among others.

Leaching Protocol. The leaching experiments employed 222 an accelerated leaching method, ${ }^{55}$ which provides a procedure 223 for measuring the leaching rate of elements from a solid 224 material. The method is based on a semidynamic dissolution 225 procedure in which the sample is immersed in a leachant for a 226 given time interval. The leachate is periodically replaced with 227 new leachant after each interval (replacement interval). The 228 experiments were conducted in cap-sealed Teflon vessels in a 229 digitally controlled oven at $90 \pm 0.5^{\circ} \mathrm{C}$ using deionized (DI) 230 water and $\mathrm{pH}$ buffer solutions. Temperature-dependent tests 231 were conducted at $20,40,70$, and $90^{\circ} \mathrm{C}$. The effect of $\mathrm{pH}$ on 232 dissolution was performed using organic buffer solutions at $\mathrm{pH} 233$ $=4$ (potassium hydrogen phthalate with formaldehyde), 6234 (citric acid with sodium hydroxide,), and 9 (borax with $\mathrm{HCl}$ ). 235 Three different sizes of Teflon vessels $(30,60$, and $120 \mathrm{~mL}) 236$ were used. The pellet geometric surface area was in the range 237 of 4 to $0.56 \mathrm{~cm}^{2}$, and surface to volume $(S / V)$ ratio was in the 238 range of 2 to $50 \mathrm{~m}^{-1}$, which remained constant during each 239 experiment as the leached fraction of the sample was negligible 240 $\left(\sim 10^{-5}\right)$ with respect to the sample. Leachant replacement 241 intervals were 1, 3.5, and 7 days. Each experiment lasted 1-3 242 weeks. Initially, sample surfaces were deeply polished after 243 leaching and reused for the following test. However, samples 244 reused with and without polishing did not show statistically 245 significant difference in the leaching rate except the first day. 246 Thus, the rest of the reused samples were not polished during 247 subsequent tests. The vessels were weighed before and after 248 each interval to monitor the solution weight loss caused by the 249 cap sealing of the Teflon vessel, which has a loss within $1 \%$ of 250 the solution mass. Acid strip was performed, and the result 251 confirmed that any deposits or sorption of leached elements on 252 the vessel were negligible.

Rate Calculation and Côté Model. The cumulative mass 254 released was calculated using eq 1 :

$$
m_{i}(n)=\sum_{j=1}^{n} m_{i, j} / S
$$

where $m_{i}(n)$ is the cumulative mass released of species $i(\mathrm{mg} / 257$ $\mathrm{m}^{2}$ ) at the $n^{\text {th }}$ interval, $m_{i, j}$ is leached amount of element $i$ in 258 milligrams of the $j^{\text {th }}$ leachate, and $S$ is the geometric surface 259 area of the sample in square meters. $m_{i, j}$ and $m_{i}(n)$ can be 260 converted to millimoles (mmol) and millimoles per square 261 meter $\left(\mathrm{mmol} / \mathrm{m}^{2}\right)$, respectively. Due to the additive nature of 262 eq 1 , the error of $m_{i}(n)$ accumulates as $n$ increases:

$$
\operatorname{error}\left[m_{i}(n)\right] \approx\left(\sum_{j=1}^{n}\left(\operatorname{error}\left[m_{i, j}\right]\right)^{2}\right)^{1 / 2} \approx \sqrt{n} \cdot \operatorname{error}\left[m_{i, j}\right]
$$

To avoid working with cumulative mass, leaching rate was 265 used for modeling using eq 3 :

$$
r_{i}(j)=m_{i, j} /\left(S t_{j}\right)
$$

where $r_{i}(j)$ is the leaching rate of species $i$ at time $j$, and $t_{j}$ is the 268 time interval at $j$. 
270 Côté model is a semiempirical mathematical model based on 271 leaching rate limiting mechanisms. ${ }^{56}$ The model was developed 272 to understand leaching mechanisms including terms attributed 273 to diffusion, dissolution, and surface effect of a solid matrix 274 material. The model has been instrumental in understanding 275 the leaching behavior of materials such as cement and ceramics 276 in aqueous solutions. ${ }^{57,58}$ The model is defined by eq $4:$

$277 \quad m(t)=k_{1} t^{1 / 2}+k_{2} t+k_{3}\left(1-\mathrm{e}^{-k_{4} t}\right)$

278 where the cumulative amount of the element of interest $m(t)$ is 279 described by the coefficient of diffusive character $k_{1}$, the 280 coefficient of constant dissolution character $k_{2}$, and coefficients 281 of surface effect $k_{3}$ and $k_{4}$. Côté and others originally proposed 282 to use regression analysis on the cumulative amount of 283 materials leached from the solid. ${ }^{569}$ Error propagation from 284 the individual measurements to the cumulative value was not 285 considered in the regression analysis. However, the accumu286 lated error could become large as the number of data points 287 increases (i.e., $\propto \sqrt{n}$ ), which makes an unambiguous 288 interpretation of the data challenging. Therefore, we use the 289 rate instead of the cumulative mass when applying the 290 regression analysis of the Côte model in this study. The 291 release rate can be expressed as eq 5 by taking a derivative of 292 eq 4 as

293

$$
r(t)=\frac{1}{2} k_{1} t^{-1 / 2}+k_{2}+k_{3} k_{4} \mathrm{e}^{-k_{4} t}
$$

294 The diffusion contribution to the rate has a $1 / \sqrt{t}$ time 295 dependence. The constant dissolution is determined by $k_{2}$, and 296 the third term, surface effect, is defined by the first-order rate 297 equation to account for rapid release of surface species into the 298 aqueous solution. ${ }^{56}$

\section{RESULTS AND DISCUSSION}

300 Effect of Solution Saturation. As shown in Supporting 301 Information Figures $S 1$ and $S 2, S / V$ ratio and leachant 302 replacement interval have a significant effect on the test 303 response. For all three elements, an increase of $S / V$ ratio 304 (Supporting Information Figure S1) causes a rate decrease as a 305 result of the solution feedback of the dissolved species, i.e., 306 reverse reaction of the dissolution reaction. For instance, as the $307 \mathrm{~S} / \mathrm{V}$ ratio increased from 5 to $50 \mathrm{~m}^{-1}$, iodine release rate 308 decreased from 5.5 to $1.1 \mathrm{mg} / \mathrm{m}^{2} / \mathrm{d}$ (Supporting Information 309 Figure S1a). Similarly, as shown in Supporting Information 310 Figure S2, an increase of the replacement interval leads to a 311 rate decrease. As the interval increases from 1 to 7 days, the 312 average release rate per day of iodine decreases from 2.5 to 0.5 $313 \mathrm{mg} / \mathrm{m}^{2} / \mathrm{d}$ because of the increased solution feedback of longer 314 intervals as a result of longer duration in the leachate solution 315 (Supporting Information Figure S2a). Lead and vanadium 316 release rates follow a similar trend as a result of the change of $317 \mathrm{~S} / \mathrm{V}$ and replacement interval.

318 In general, an increase of $S / V$ or interval generates a solution 319 with more dissolved species, which causes the chemical 320 potentials of dissolved species and the solution saturation 321 state to increase, resulting in an increase of the free energy of 322 dissolution (less negative), a decrease of free energy driving 323 force (chemical affinity), and a reduced dissolution rate. Such a 324 solubility-controlled kinetics of dissolution is well-documented 325 in the literature for ceramics and minerals. ${ }^{60-63}$ With 326 assumptions of transition state theory ${ }^{64,65}$ and principle of detailed balance, ${ }^{66,67}$ the dependence of dissolution rate on 327 free energy driving force follows eq 6 :

$$
r=k_{f}\left(1-\mathrm{e}^{(\Delta G / R T)}\right)=k_{f}(1-(Q / K))
$$

where $k_{f}$ is forward rate constant, $\Delta G$ is the free energy of the 330 dissolution reaction, $R$ is gas constant, $T$ the temperature, $Q 331$ the activity product, $K$ the equilibrium constant, and $Q / K$ the 332 saturation index. To account for the overall reaction related to 333 the activated surface complex, Temkins average stoichiometric 334 number $n$ was introduced: ${ }^{61,62,68}$

$$
r=k_{f}\left(1-\mathrm{e}^{(n \Delta G / R T)}\right)=k_{f}\left(1-(Q / K)^{n}\right)
$$

To account for the effect of crystal defects on dissolution, an 337 exponent $m$ was introduced: ${ }^{61,62,68}$

$$
r=k_{f}\left(1-\mathrm{e}^{(\Delta G / R T)}\right)^{m}=k_{f}(1-(Q / K))^{m}
$$

To accommodate both reaction stoichiometry and defects, 340 the constants $n$ and $m$ can be applied at the same time. ${ }^{61,62,68} 341$ The defects here, in general, refer to the surface defects that 342 lead to complex surface dissolution phenomena, ${ }^{62,68}$ for 343 instance, etch pit formation from a screw dislocation. These 344 equations that relate a dissolution rate to the free energy 345 driving force (saturation index) are well established. 346 Furthermore, a mechanistic-based analytical form that can 347 relate dissolution rate to experimental control parameters such 348 as $S / V$ ratio and leachant replacement interval in a semi- 349 dynamic leaching experiment should exist and be well-defined. 350 Such a relation can be instrumental for normalization of the 351 test results carried out at different $S / V$ and interval values. In 352 addition, when parametrized, such a relation can then be used 353 to predict the release rate under various $S / V$ and leachant 354 replacement intervals that mimic different disposal conditions. 355

As shown in Figure 2, the effects of the inverse of $S / V$ ratio $356 \mathrm{f} 2$ and interval are not linear. As $V / S$ ratio or 1 /interval becomes 357

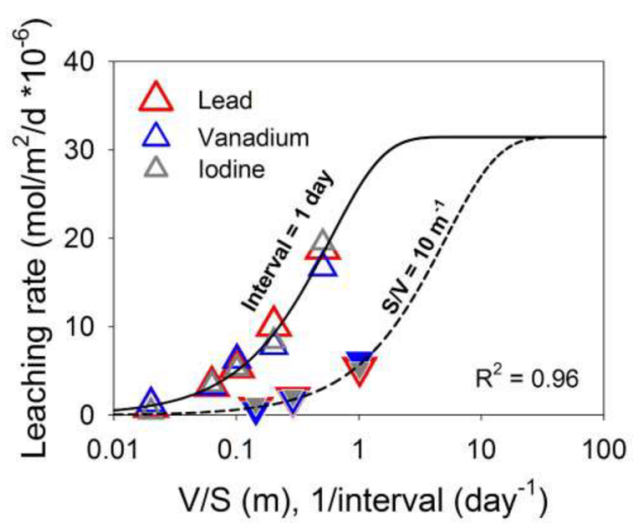

Figure 2. Effect of the reciprocal of the test parameters $(V / S$ and $1 /$ interval) on the release rates of lead, vanadium, and iodine. The lines are the fitted result of eq 9 of leaching rate data with interval $=1$ day (solid lines and symbols) and the data with $S / V=10 \mathrm{~m}^{-1}$ (dashed lines and filled symbols). The rates were normalized to the stoichiometry of iodoapatite.

zero, the rate is expected to tend to zero. As $V / S$ ratio or $1 / 358$ interval approaches to infinity, the rate is expected to reach the 359 maximum value established by the dissolution reaction kinetics 360 without attenuation by solution feedback. Such boundary 361 conditions can be approximated by a single exponential 362 
363 function with a three parameter rise to maximum in the form 364 of

$$
365 \quad r\left(p_{s}\right)=k_{S}\left(1-\mathrm{e}^{-\phi p_{s}}\right)^{m}
$$

366 where $r\left(p_{s}\right)$ is rate, $p_{s}$ is saturation control parameter (1/ 367 interval or $V / S$ ), $k_{S}$ is the maximum rate (or forward rate 368 constant), and $\phi$ is constant for a given saturation control 369 parameter. Note that $V / S$ ratio and 1 /interval are used because 370 of the construction of eq 9 . For iodoapatite, $m$ is close to 1.0 371 after fitting experimental data with eq 9 without constraints. 372 Similarity of the mathematical form between eqs 7 and 9 373 suggests an underlying assumption: saturation control 374 parameter $\left(p_{s}\right)$ is linearly proportional to the free energy of 375 the dissolution reaction. Although such an assumption is 376 simplistic, in the absence of an analytical form to describe their 377 relationship, the equation models the boundary conditions 378 correctly: as $p_{s}$ approaches zero, the rate of dissolution 379 approaches zero, and as $p_{s}$ increases, the rate gradually reaches 380 a plateau and approximately becomes a constant. Such 381 behavior has been observed for a number of dissolution 382 experiments using flow-through method. ${ }^{69-71}$ Therefore, eq 9 383 was used to fit the 1 /interval and $V / S$ test data simultaneously 384 with the plateau values for the 1 /interval and $V / S$ constrained 385 to be the same. Regression equations with a $R^{2}$ of 0.96 were 386 attained by using $k_{S}=31.5 \pm 4.1 \times 10^{-6} \mathrm{~mol} / \mathrm{m}^{2} / \mathrm{d}$ and $\phi=$ $3871.7 \pm 0.3 \mathrm{~m}^{-1}$ for $V / S$, and $0.20 \pm 0.03$ day for $1 /$ interval. As 388 shown in Figure 2, these equations can be used to normalize 389 the rates measured in leaching experiments conducted at 390 different intervals and $S / V$ ratios to account for differences in 391 solution saturation.

392 Time Dependence of lodine Release. Molar ratio I/Pb 393 in leachate solutions as a function of time is plotted in Figure $3943 \mathrm{a}$. The ratio decreases with time and gradually approaches the 395 stoichiometric ratio of iodoapatite (0.17). There is a $\sim 10$-fold 396 decrease of the ratio measured in the test solution from the 397 initial value of 1.7 . In contrast, the $\mathrm{V} / \mathrm{Pb}$ ratio (Supporting 398 Information Figure S3) remains constant in the test solutions 399 with a stoichiometric ratio of $\mathrm{V} / \mathrm{Pb}(0.61)$ within the error $400(\sim 28 \%)$, which is estimated using an error propagation 401 equation similar to eq 2 . In order to check if there was any 402 precipitations or adsorptions during leaching tests that might 403 have altered the molar ratios of the dissolved species, SEM was 404 performed on the sample surfaces (Figures $1 \mathrm{~b}-\mathrm{d}$ ) and acid 405 strip tests were carried out on the Teflon vessels, respectively. 406 The results showed there were no precipitates on the sample 407 surfaces and no detectable amounts of $\mathrm{Pb}, \mathrm{V}$, or I present in 408 the strip solutions. Thermodynamic calculations using 409 MINTEQ $^{72}$ confirmed that the leachate solutions were 410 undersaturated with respect to all relevant low solubility 411 solid phases including $\mathrm{Pb}_{2} \mathrm{~V}_{2} \mathrm{O}_{7}$ and $\mathrm{Pb}_{3}\left(\mathrm{VO}_{4}\right)_{2}$. The difference 412 between the measured and the stoichiometric $\mathrm{I} / \mathrm{Pb}$ molar 413 ratios indicates the release of iodine is incongruent with 414 respect to $\mathrm{Pb}$ and $\mathrm{V}$, which is consistent with our previous 415 study based on 3-week-long experiments. ${ }^{40}$ Similar iodine 416 release behaviors were also observed in other studies of 417 iodoapatite dissolution reported in the literature. ${ }^{47,48}$ The 418 incongruent release behavior of iodine originated from the 419 chemistry of iodoapatite where iodide is more ionic bonded at 420 the channel in the apatite structure site, while lead and 421 vanadium are more covalently bonded. ${ }^{73}$ Such bonding 422 difference leads to different leaching behavior.
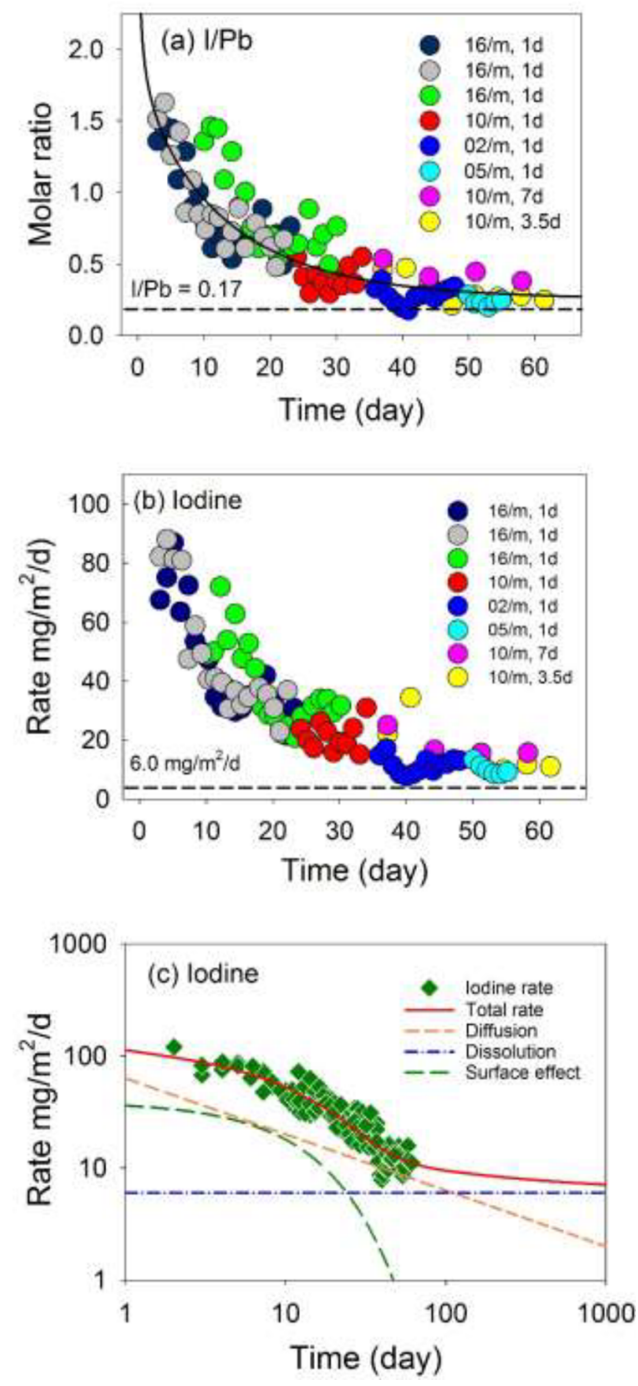

Figure 3. (a) $\mathrm{I} / \mathrm{Pb}$ molar ratio in leached solutions as a function of time. The data points are from the experiments with different $S / V$ ratios and intervals using DI water at $90{ }^{\circ} \mathrm{C}$. The solid line is the fitted result using eq 5. The horizontal dashed-line is the stoichiometric I/ $\mathrm{Pb}$ ratio of iodoapatite. (b) Iodine leaching rate normalized to $S / V=$ $1 \mathrm{~m}^{-1}$ and interval $=1$ day using DI water at $90^{\circ} \mathrm{C}$. The dashed-line is iodine long-term release rate. Insets in (a) and (b) include $S / V$ and interval values. (c) Côté fitting result of the iodine release rate data normalized to interval $=1$ day and $S / V=1 \mathrm{~m}^{-1}$ as a function of time using DI water at $90{ }^{\circ} \mathrm{C}$ based on eq 5 . Symbols are experiment data. The solid line (red) is the total release rate, the short-dashed line (orange) is the contribution from the diffusion term, the long-dashed line (green) is from the surface effect term, and the dot-dashed line (blue) is from the constant dissolution.

In order to directly compare the release rates based on 423 experiments using different test parameters (i.e., $S / V$ ratio and 424 interval), the rates were normalized by $S / V$ and replacement 425 interval. For $\mathrm{Pb}$ and $\mathrm{V}$, the normalization is straightforward 426 using eq 9 since releases of these two elements are constant 427 over time. However, I release rate is time dependent (Figure 428 3a), which needs to be normalized first. The Côté equation (eq 429 5) was used to normalize the time dependence. To eliminate 430 the effect of test conditions, $\mathrm{I} / \mathrm{Pb}$ ratio (i.e., iodine release rate 431 normalized to $\mathrm{Pb}$ ) was used for this normalization. As shown 432 in Figure $3 \mathrm{a}, \mathrm{I} / \mathrm{Pb}$ ratio was fitted well with eq 5 . This fitted 433 equation was then used to normalize the iodine rate measured 434 
435 at a given time to its long time rate when iodine release rate 436 would be congruent with respect to $\mathrm{Pb}$ and $\mathrm{V}$. And then, the 437 release rates of all three elements were normalized to $S / V=1$ $438 \mathrm{~m}^{-1}$ and interval $=1$ day, and plotted for I (Figure $3 \mathrm{~b}$ ), V 439 (Supporting Information Figure $\mathrm{S} 4 \mathrm{a}$ ), and $\mathrm{Pb}$ (Supporting 440 Information Figure S4b). Based on the normalized rate, iodine 441 release rate was fitted with eq 5 of Côté model. As shown in 442 Figure 3c, both diffusion and surface effects have significant 443 initial contributions to the total release of iodine, but the 444 surface effect becomes negligible after about 2 weeks and 445 constant dissolution becomes the dominant process after 446 approximately 100 days. This analysis predicts the long-term 447 iodine release rate will eventually become controlled by the 448 constant matrix dissolution rate, which is $\sim 6.0 \mathrm{mg} / \mathrm{m}^{2} / \mathrm{d}$ at 449 conditions of $\mathrm{pH} 7, S / V=1 \mathrm{~m}^{-1}$ and interval $=1$ day using DI 450 water and $90{ }^{\circ} \mathrm{C}$. Note that the long-term I release rate is 451 significantly lower than the rate measured in short-term 452 laboratory tests, which is controlled by a transient diffusion 453 process (surface effect). The parametrized eq 5 can thus be 454 used to predict the time dependent release of iodine from the 455 iodoapatite.

456 Effect of Temperature. Temperature effect on the 457 iodoapatite dissolution rate is plotted in Supporting 458 Information Figure S5. Same experimental protocol was 459 employed using DI water as leachant with 1 day interval and $460 \mathrm{~S} / \mathrm{V}$ of $5.0 \mathrm{~m}^{-1}$. The temperatures were $20.0,40.0,70.0$, and $46190.0{ }^{\circ} \mathrm{C}$. The release rates of all three elements increase with 462 temperature. The temperature effect is better understood by 463 plotting the logarithm of the rate as a function of inverse 464 temperature based on the Arrhenius eq (Figure 4a):

$465 \quad r(T)=A \mathrm{e}^{-E_{\mathrm{a}} / R T}$

466 where $A$ is the pre-exponential factor, $R$ the gas constant, $T$ the 467 temperature in $\mathrm{K}$, and $E_{a}$ the activation energy. The activation 468 energy was extracted from a linear fit (Figure $4 \mathrm{a}$ ) to be $22.2 \pm$ $4690.9 \mathrm{~kJ} / \mathrm{mol}$ for iodine and $16.9 \pm 2.5 \mathrm{~kJ} / \mathrm{mol}$ for $\mathrm{Pb}$ and $\mathrm{V}$. The 470 leachant change interval and $S / V$ ratio were kept constant to 471 minimize the saturation effect on the rates, which is neglected 472 in this study. If all three elements were released stoichiometri473 cally in the same chemical process, the activation energy 474 derived using each element should be the same. Since lead and 475 vanadium are dissolved congruently, their activation energy 476 represents the dissolution rate of iodoapatite matrix. For 477 iodine, both diffusion and dissolution contribute the iodine 478 release (Figure 3c). The activation energy from fitting the 479 iodine curve in Figure $4 \mathrm{a}$ accounts for both processes. The 480 diffusion portion of iodine release can be approximately 481 extracted by subtracting the constant dissolution contribution 482 given by the $\mathrm{Pb}$ or $\mathrm{V}$ rate from the iodine release rate. By 483 attributing the difference in the data to diffusion, an activation 484 energy of $34.4 \pm 3.9 \mathrm{~kJ} / \mathrm{mol}$ was then obtained for the 485 diffusion process, which is similar to the previously reported 486 value of $37 \pm 4 \mathrm{~kJ} / \mathrm{mol}$ based on the initial release rate in pure 487 water at 25,50 , and $90{ }^{\circ} \mathrm{C}$ when at the initial stage the 488 diffusion is the dominant contribution to the release. ${ }^{47}$ Note 489 that the estimated activation energy for dissolution of 490 iodoapatite matrix is lower than for the iodide diffusion, 491 which is counterintuitive. However, the activation energies are 492 consistent with a reported dissolution experiment of 493 iodoapatite conducted at $\mathrm{pH}$ values $5.5-6$ and 4.1 at different 494 temperatures. ${ }^{50}$ Based on those experimental results, the 495 activation energy at $\mathrm{pH} 5.5-6$ is higher than at 4.1 . $^{50}$ Since 496 iodide diffusion is $\mathrm{pH}$ independent, the activation energy
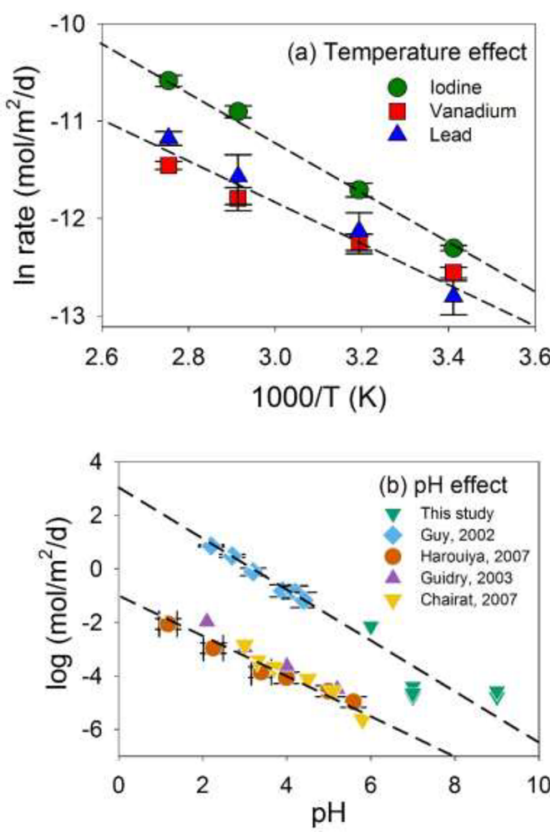

Figure 4. (a) Arrhenius plot of logarithm rates as a function of inverse temperature. The dashed lines are fitted lines. The rates were normalized to the stoichiometry of iodoapatite. (b) Dissolution rates as a function of solution $\mathrm{pH}$ for iodoapatite and natural apatite. The experimental data of natural apatite were obtained at far-fromequilibrium conditions at $25{ }^{\circ} \mathrm{C}$. The data for iodoapatite were scaled to far-from-equilibrium conditions and $25{ }^{\circ} \mathrm{C}$ based on $S / V$ ration and interval, and the activation energy. All rates are normalized by the stoichiometry of the apatite. The dashed lines are the results of linear fitting.

derived from the lower $\mathrm{pH}$ data has more contribution from 497 dissolution because of the higher dissolution rate of iodoapatite 498 at the lower $\mathrm{pH}$. At higher $\mathrm{pH}$ values such as $\mathrm{pH} 9$, the 499 activation energy becomes increasingly influenced by the 500 diffusion process as the dissolution rate decreases. 501

In an effort to cross-check the activation energy of iodide 502 diffusion in apatite structure, first-principles calculations were 503 carried out to estimate the migration energy of iodide along 504 channels in iodoapatite structure. The calculations were based 505 on density functional theory and plane wave basis sets as 506 implemented in VASP. ${ }^{74}$ Projector-augmented wave method ${ }^{75} 507$ and exchange-correlation as parametrized by Perdew-Wang 508 functional ${ }^{76,77}$ were applied in the generalized gradient 509 approximation. $^{78}$ The computations employed a $2 \times 2 \times 2510$ supercell and the k-meshes were generated in the Brillouin 511 zone with a $1 \times 1 \times 2$ Monkhorst-Pack grid. The energy 512 cutoff was set as $520 \mathrm{eV}$. A vacancy-based migration 513 mechanism was assumed. Nudged elastic band method was 514 used for the calculations. ${ }^{79}$ The calculated migration energy is 515 $0.33 \mathrm{eV}$ or $31.9 \mathrm{~kJ} / \mathrm{mol}$, which is consistent with the activation 516 energy $34.4 \pm 3.9 \mathrm{~kJ} / \mathrm{mol}$ from this study and $37 \pm 4 \mathrm{~kJ} / \mathrm{mol} 517$ reported in the literature. ${ }^{47}$

518

The activation energy for iodoapatite matrix dissolution at 519 pH 7 using DI water $(16.9 \mathrm{~kJ} / \mathrm{mol})$ is low and less than half of 520 the reported values of natural apatite $\left(\mathrm{Ca}_{10}\left(\mathrm{PO}_{4}\right)_{6} \mathrm{~F}_{2}\right)$, which 521 are in the range of 34.7 to $46.0 \mathrm{~kJ} / \mathrm{mol}^{70,80}$ For natural 522 fluorapatite, an activation energy of $46.0 \mathrm{~kJ} / \mathrm{mol}$ was extracted 523 from experiments at temperatures of 5,25 , and $50{ }^{\circ} \mathrm{C}$, and $\mathrm{pH} 524$ from 1 to 6 using closed-system reactors. ${ }^{80}$ For a similar 525 natural apatite, $\mathrm{Ca}_{10}\left(\mathrm{PO}_{4}\right)_{6} \mathrm{~F}_{2}$, an activation energy $34.7 \pm 1.6526$ 
$527 \mathrm{~kJ} / \mathrm{mol}$ was reported from experiments at 25,35 , and $55{ }^{\circ} \mathrm{C}$ 528 and $\mathrm{pH}$ of 3.0 using a flow-through method. ${ }^{70}$ Although 529 natural fluorapatite and iodoapatite have the same crystal 530 structure, they have different chemical compositions. The 531 difference in the activation energies of the two apatite 532 compositions is related to difference in the chemical bonding 533 and crystal chemistries of the materials. Ionic radius of $\mathrm{Pb}^{2+}$ is $5341.19 \AA, 0.36 \AA$ for $\mathrm{V}^{5+}$, and $2.20 \AA$ for $\mathrm{I}^{-}$of iodoapatite, 535 corresponding to $1.00 \AA$ for $\mathrm{Ca}^{2+}, 0.17 \AA$ for $\mathrm{P}^{5+}$, and 1.33 for $536 \mathrm{~F}^{-}$of natural apatite, or $13 \%, 53 \%$, and $40 \%$ decreases, 537 respectively, from iodoapatite to natural apatite. The decrease 538 causes an increase in the ionic potential at each crystallo539 graphic site, increase in the chemical bonding strength, and 540 decrease in bond distances, as reflected in the unit cell volume, 541 which is $702.39 \AA^{3}$ for iodoapatite, ${ }^{81}$ and $527.91 \AA^{3}$ for 542 fluorapatite $^{82}$ or $25 \%$ decrease. The stronger bonding and 543 shorter bond distance lead to a higher activation energy for 544 fluorapatite dissolution than for iodoapatite.

545 Effect of $\mathbf{p H}$. The cumulative mass released in solution as a 546 function of time is plotted in Supporting Information Figure S6 547 for tests conducted at different $\mathrm{pHs}$. The rates for all elements 548 are significantly higher at low $\mathrm{pH}$ values over the $\mathrm{pH}$ range 4549 9, which is consistent with previous leaching test results. ${ }^{47}$ 550 Dissolution rates are low in DI water and at $\mathrm{pH}$ 9. Lead was 551 not detected in the leachates of the experiment at $\mathrm{pH}$ 9. In 552 both cases, individual grains of the leached surface became 553 exposed as a result of grain boundary dissolution, as shown by 554 the SEM image (Figure $1 \mathrm{~b}$ ). At $\mathrm{pH} \mathrm{6,} \mathrm{the} \mathrm{dissolution} \mathrm{rate}$ 555 increased by more than 2 orders of magnitude from that at $\mathrm{pH}$ 5569 . The surfaces were dramatically corroded with severe 557 roughness and grain boundaries deeply exposed (Figure 1c). 558 No secondary phases were observed on the surfaces. At $\mathrm{pH} 4$, a 559 large fraction of the surface became covered by precipitates of 560 a secondary phase (Figure 1d). Severe corrosion is visible 561 where the surface is not blocked by the precipitates (top right 562 and bottom left corners of Figure 1d). Using Raman 563 spectroscopy, the precipitated phase was identified to be 564 chervetite $\left(\mathrm{Pb}_{2} \mathrm{~V}_{2} \mathrm{O}_{7}\right)$ as shown in Supporting Information 565 Figure S7. Although it is expected that the dissolution rate at $566 \mathrm{pH} 4$ should be much higher than at $\mathrm{pH} 6$, the measured rates 567 of all three elements in the solution are actually lower at $\mathrm{pH} 4$ 568 than those at $\mathrm{pH} 6$ because of the precipitation of chervetite 569 and reduced surface area accessible to the solution (Supporting 570 Information Figure S6, Figure 1d). The I release rate is slightly 571 lower at $\mathrm{pH} 4$ than at $\mathrm{pH}$ 6, but the solution-based rates for $\mathrm{Pb}$ 572 and $\mathrm{V}$ at $\mathrm{pH} 4$ are less than half of those at $\mathrm{pH} 6$ because a 573 significant amount was precipitated in chervetite. It needs to be 574 emphasized that the calculated rate based on solution 575 concentrations and initial surface area does not represent the 576 dissolution rate for elements sequestrated in secondary phases. 577 A thermodynamic calculation based on measured concen578 trations of the leachate solutions using MINTEQ confirmed 579 that chervetite was supersaturated with respect to the dissolved 580 species at $\mathrm{pH} 4$. No other secondary phases were observed on 581 the leached surfaces at $\mathrm{pH} 4$ based on SEM images and Raman 582 spectra.

583 The effect of $\mathrm{pH}$ on natural apatite dissolution is well 584 documented in the literature. ${ }^{70,80,83}$ In general, dissolution rate 585 decreases as $\mathrm{pH}$ increases from acidic to near neutral 586 conditions, which is often modeled by eq 11 :

587

$$
r(\mathrm{pH})=k_{\mathrm{pH}}^{0}\left[H^{+}\right]^{\eta}=k_{\mathrm{pH}}^{0} 10^{-\eta \cdot \mathrm{pH}}
$$

where $k_{\mathrm{pH}}^{0}$ is a constant and $\eta$ is the exponent. As shown in 588 Figure $4 \mathrm{~b}$, the logarithm of the rate is a linear function of $\mathrm{pH} .589$ By fitting of the data, $k_{\mathrm{pH}}^{0}$ and $\eta$ were determined to be $10^{2.8 \pm 0.5} 590$ and $0.87 \pm 0.08$, respectively, for iodoapatite. For natural 591 apatite, the $k_{\mathrm{pH}}^{0}$ and $\eta$ values were determined to be $10^{-0.9 \pm 0.2} 592$ and $0.75 \pm 0.05$ based on the literature data. ${ }^{70,80,84}$ Similar $\eta 593$ values have been reported for natural apatite, 0.8 for apatite 594 $\mathrm{Ca}_{10}\left(\mathrm{PO}_{4}\right)_{6}\left(\mathrm{~F}_{1.4}, \mathrm{OH}_{0.6}\right)_{2},{ }^{83} 0.6$ for apatite $\mathrm{Ca}_{10}\left(\mathrm{PO}_{4}\right)_{6} \mathrm{~F}_{2},{ }^{80}{ }_{595}$ and0.81 for apatite $\mathrm{Ca}_{10}\left(\mathrm{PO}_{4}\right)_{6} \mathrm{~F}_{2} \cdot{ }^{70}$ Since the empirical $\eta 596$ value is interpreted as the order of the dissolution reaction with 597 respect to $\mathrm{pH}$, it is reasonable to expect that both natural 598 apatite and iodoapatite have a similar dissolution reaction 599 mechanism. However, the $k_{\mathrm{pH}}^{0}$ value is near 3 orders of 600 magnitude higher for iodoapatite than natural apatite. Similar 601 to the difference in the activation energy of dissolution 602 between natural apatite and iodoapatite, the higher dissolution 603 rate of iodoapatite as reflected in the $k_{\mathrm{pH}}^{0}$ value at a given $\mathrm{pH}$ is 604 a result of the weaker chemical bonding in iodoapatite. 605

Results presented above suggest iodoapatite is much less 606 durable than natural apatite, given that iodine release rates 607 from iodoapatite are about 3 orders of magnitude higher than 608 natural fluorapatite, and with an activation energy about half of 609 the natural fluorapatite. In addition, the $\mathrm{Pb}-\mathrm{V}$ iodoapaptite 610 has a low melting point and relatively low iodine weight 611 loading capacity $(\sim 8 \mathrm{wt} \%)$. However, the fact that the 612 compositional space of iodoapatite has not been fully explored 613 means new apatite compositions that incorporate more iodine 614 and have better chemical durability and physical properties are 615 possible. Based on an artificial neural network simulation, a 616 number of iodoapatite compositions may be able to 617 incorporate iodine. ${ }^{43}$ Since an increased chemical bonding 618 strength enhances chemical durability and increases the 619 activation energy of the dissolution, apatites with elements 620 having a smaller ionic radii than $\mathrm{Pb}$ and $\mathrm{V}$, such as $\mathrm{Sr}, \mathrm{Ca}, \mathrm{Cd}, 621$ and $\mathrm{Zn}$ for $\mathrm{Pb}$, and $\mathrm{Cr}, \mathrm{As}, \mathrm{Si}$, and $\mathrm{P}$ for $\mathrm{V}$, are expected to have 622 higher activation energies for dissolution and increased 623 chemical durability.

624

Prediction of lodoapatite Dissolution. Dissolution rate 625 of iodoapatite can be described by combining equations 5, 9, 626 10 , and 11 , resulting in eq 12 below:

627

$$
\begin{aligned}
r\left(t, p_{s}, T, \mathrm{pH}\right)= & r(t) A k_{S} k_{\mathrm{pH}}^{0} \times 10^{-\eta \cdot \mathrm{pH}}\left[\mathrm{e}^{-E_{\mathrm{a}} / R T}\right] \\
& {\left[1-\mathrm{e}^{-\phi p_{s}}\right] }
\end{aligned}
$$

where $t, p_{s}, T, \mathrm{pH}$ are time, the experimental test parameter 629 that controls the solution saturation, solution temperature, and 630 solution $\mathrm{pH}$. The empirical parameter $A, k_{S}$, and $k_{\mathrm{pH}}^{0}$ are the 631 pre-exponential factor of Arrhenius equation, dissolution rate 632 constant, and rate constant at $\mathrm{pH}=0$, respectively. The terms 633 $\eta, R, E_{a}$, and $\phi$ are the order of dissolution reaction with 634 respect to $\mathrm{pH}$, the gas constant, the activation energy for 635 dissolution, and a constant related to saturation, respectively. 636

The $r(t)$ term in eq 12 is described in eq 5, which addresses 637 the time dependence for elemental release. For lead and 638 vanadium, $r(t)=k_{2}$, a constant, in eq 5. For iodine, $r(t)$ is 639 initially dominated by the diffusion term $\left(\frac{1}{2} k_{1} t^{-1 / 2}\right)$ and a 640 significant contribution from the surface effect $\left(k_{3} k_{4} \mathrm{e}^{-k_{4} t}\right), 641$ then becomes dominated by the constant dissolution term $\left(k_{2}\right) 642$ at longer times. As a result of different release mechanisms, the 643 terms in eq 5 have different $p H, T$, and saturation dependences 644 for different elements. Since these processes occurred 645 simultaneously, accurately estimating the parameters for the 646 
647 individual mechanisms is challenging. However, it is under648 stood that iodine diffusion in bulk iodoapatite is independent 649 of both $\mathrm{pH}$ and the saturation state of the leachant solution. 650 The temperature dependence of iodine diffusive release is 651 controlled by the activation energy of the diffusion in the 652 channel. For iodide release contributed by matrix dissolution, 653 its $\mathrm{pH}$ and $\mathrm{T}$ dependences should be the same as those for lead 654 and vanadium. The $\mathrm{pH}$ and $T$ dependences of the short-term 655 surface effect is expected to be similar to all three elements for 656 the dissolution. The final parametrized empirical values at 90 $657{ }^{\circ} \mathrm{C}, 1$ day interval, $S / V=1 \mathrm{~m}^{-1}$, and $\mathrm{pH}=7$ are listed in 658 Supporting Information Table S1. Examples of predictions at 659 two given sets of conditions are illustrated in Figure 5.
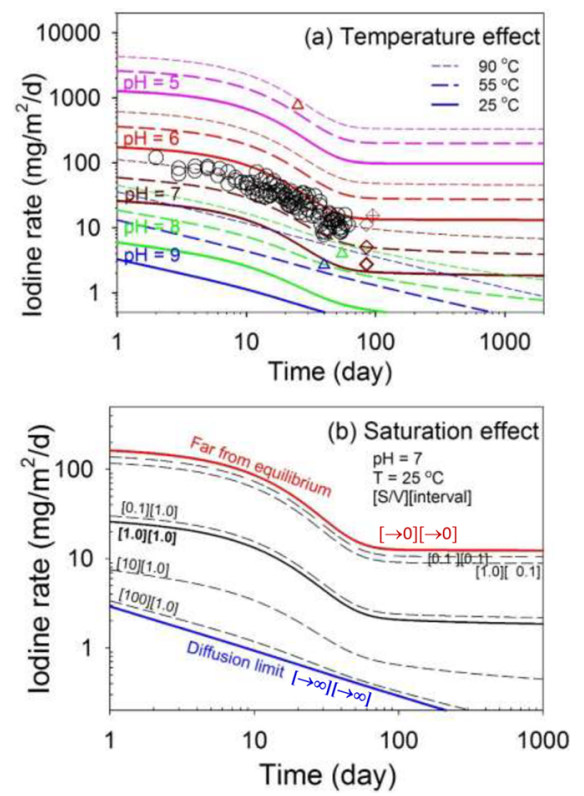

Figure 5. (a) Prediction of iodine release rate as a function of time at different $\mathrm{pHs}$ and temperatures under the conditions of $S / V=1 \mathrm{1} / \mathrm{m}$ and interval $=1$ day. The lines are predictions using eq 12 . The symbols are experiment data. Open circles are the measured rates using DI water at $90{ }^{\circ} \mathrm{C}$ and normalized to $S / V=11 / \mathrm{m}$ and interval $=1$ day. The triangles are data at $90{ }^{\circ} \mathrm{C}$ and $\mathrm{pH} 9$ (blue), $\mathrm{pH} 7$ (green), and $\mathrm{pH} 6$ (red). The brown diamonds are data at $\mathrm{pH} 7$ and temperatures from $20{ }^{\circ} \mathrm{C}$ (thick edge), $50{ }^{\circ} \mathrm{C}$ (medium thick edge), $70{ }^{\circ} \mathrm{C}$ (thin edge), and $90{ }^{\circ} \mathrm{C}$ (thin edge with a cross). (b) Prediction of iodine release rate as a function of time at different $S / V$ ratios and intervals under the condition of $\mathrm{pH}=7$ and temperature of $25{ }^{\circ} \mathrm{C}$. The $S / V$ ratio and interval are indicated. The lines are predictions using eq 12 . The high release rate line marks the far-from-equilibrium limit (thick red line), and the low release rate line is diffusion limit (thick blue line).

660 Figure 5a shows a prediction of parametrized eq 12, which 661 highlights the effects of temperature and $\mathrm{pH}$ on the iodine 662 release rate under test conditions of $S / V=1 \mathrm{~m}^{-1}$ and interval $=$ 6631 day. $\mathrm{pH}$ has a significant effect on iodine release rate. The 664 initial rate increases about 3 orders of magnitude from $\mathrm{pH} 9$ 665 (blue curves) to 5 (pink curves). At low $\mathrm{pHs}$, the release rate is 666 quite high, with contributions from dissolution, diffusion, and 667 surface effects, and exceeds $3000 \mathrm{mg} / \mathrm{m}^{2} / \mathrm{d}$ at $90{ }^{\circ} \mathrm{C}$ and $\mathrm{pH} 5$ 668 after 1 day. The initial release rates are very low at $\mathrm{pH} 8$ (green 669 curves) and $\mathrm{pH} 9$ (blue curves), as low as $\sim 3 \mathrm{mg} / \mathrm{m}^{2} / \mathrm{d}$ at 25 $670{ }^{\circ} \mathrm{C}$ and $\mathrm{pH} 9$ after 1 day (solid blue curve), at which point the 671 iodine release rate is dominated by diffusion (Figure 5a). The iodine release becomes controlled by constant dissolution at 672 pH 7 (brown curves), pH 6 (red curves), pH 5 (pink curves), 673 and $\mathrm{pH} 8$ (green curves at low temperatures) after $\sim 100$ days, 674 but remains controlled by diffusion at $\mathrm{pH} 9$ (blue curves) 675 beyond 1000 days. Figure $5 \mathrm{~b}$ shows a prediction of solution 676 saturation effect (i.e., $S / V$ ratio and leachant replacement 677 interval) based on the parametrized eq 12 at $\mathrm{pH}$ of 7 and 678 temperature of $25{ }^{\circ} \mathrm{C}$. As $S / V$ ratio and interval become 679 smaller, the iodine release rate increases, approaching the far- 680 from-equilibrium limit where dissolution is dominated, 681 represented by the thick red line (Figure $5 \mathrm{~b}$ ). While as the 682 $S / V$ and interval become larger, the iodine release rate 683 decreases and approaches the diffusion limit when the diffusion 684 is dominated, represented by the thick blue line (Figure 5b). In 685 the short term, the effect of $S / V$ ratio and interval on the 686 iodine release rate can reach as high as 2 orders of magnitude 687 for the difference between a diffusion limit line at high $S / V 688$ ratios and large intervals (e.g., $S / V>100 \mathrm{~m}^{-1}$ and interval $>1689$ day) and far-from-equilibrium line (e.g., $S / V<0.1 \mathrm{~m}^{-1}$ and 690 interval $<0.1$ day). In the long term, iodine release under far- 691 from-equilibrium condition is controlled by dissolution, with a 692 release rate of up to about $10 \mathrm{mg} / \mathrm{m}^{2} / \mathrm{d}$ (long-term maximum 693 rate). Under the conditions near the diffusion limit line, the 694 release rate diminishes quickly to below $0.1 \mathrm{mg} / \mathrm{m}^{2} / \mathrm{d}$ (long- 695 term minimum rate).

696

\section{SUMMARY AND CONCLUDING REMARKS}

697

A systematic chemical durability study of iodoapatite was 698 carried out under semidynamic conditions using DI water and 699 $\mathrm{pH}$ buffering solutions at various surface-to-volume ratios, 700 leachant replacement intervals, and temperatures. The results 701 were utilized to parametrize a combined dissolution rate 702 equation (master equation) that takes into account the critical 703 dissolution processes of diffusion, dissolution, and surface 704 artifacts. The time-dependent process was estimated using a 705 semiempirical model based on rate limiting mechanisms. The 706 effect of solution saturation state on the dissolution rate was 707 modeled with a function that relates the saturation state with 708 the surface-to-volume ratio and leachant replacement interval. 709 By placing the experimental leaching test results in the 710 mechanistically based models, the parametrized general 711 equation was then used to predict the release rate for each 712 of the constituent elements under various environmental 713 conditions. The result suggests that the long-term iodine 714 release rate is significantly lower than the rate measured in 715 short-term laboratory tests, which is controlled by a transient 716 diffusion process and surface effect. The result demonstrates 717 that it is possible to parametrize a model by considering all 718 critical processes and environmental variables and to predict 719 the performance of a ceramic waste form such as iodoapatite 720 and other nuclear waste forms under various environmental 721 conditions. Applying the methodology employed in this study 722 to other viable iodine waste forms would provide a consistent 723 data set on their chemical durability and dissolution kinetics. 724 Such a data set can be used to establish practical iodine waste 725 forms among those proposed in the literature.

\section{ASSOCIATED CONTENT}

The Supporting Information is available free of charge on the 729 ACS Publications website at DOI: 10.1021/acsearthspace- 730 chem. 8 b00162. 
732 Parameters used in eq 12 for prediction of iodine 733 release; cumulative dissolved mass as a function of time $734 \quad$ with different $S / V$ ratios, and leachant change intervals 735 for $\mathrm{Pb}, \mathrm{V}$, and $\mathrm{I} ; \mathrm{V} / \mathrm{Pb}$ ratio as a function of time, and 736 normalized rate for $\mathrm{V}$ and $\mathrm{Pb}$; cumulative dissolved mass 737 released as a function of time at different temperatures 738 and pHs; Raman spectra of leached surface and 739 chervetite precipitate (PDF)

\section{$740 \square$ AUTHOR INFORMATION}

\section{Corresponding Author}

742 *Phone: 225-578-5532. Fax: 225-578-2302. E-mail: jianwei@ 743 lsu.edu.

\section{ORCID 1}

745 Jianwei Wang: 0000-0001-7671-0533

746 Notes

747 The authors declare no competing financial interest.

\section{ACKNOWLEDGMENTS}

749 This work was supported as part of the Center for Performance 750 and Design of Nuclear Waste Forms and Containers, an 751 Energy Frontier Research Center funded by the U.S. 752 Department of Energy, Office of Science, Basic Energy 753 Sciences, under Award DE-SC0016584. The computation 754 used resources of the National Energy Research Scientific 755 Computing Center, a DOE Office of Science User Facility 756 supported by the Office of Science of the U.S. Department of 757 Energy under Contract No. DE-AC02-05CH11231. Portions 758 of the computation were conducted with high performance 759 computing resources provided by Louisiana State University 760 (http://www.hpc.lsu.edu). We also acknowledge the Shared 761 Instrumentation Facilities (SIF) and Center for Advanced 762 Microstructures and Devices (CAMD) at LSU for material 763 characterization.

\section{REFERENCES}

765 (1) Management and Disposal of U.S. Department of Energy Spent 766 Nuclear Fuel, a report to the United States Congress and the Secretary 767 of Energy; U.S. Nuclear Waste Technical Review Board: 2017.

768 (2) Gagarinskii, A. Y. Blue ribbon commission on america's nuclear 769 future. At. Energy 2012, 112 (4), 307-309.

770 (3) Ewing, R. C. Long-term storage of spent nuclear fuel. Nat. Mater. $7712015,14,252$.

772 (4) Kleykamp, H. The chemical state of the fission products in oxide 773 fuels. J. Nucl. Mater. 1985, 131 (2-3), 221-246.

774 (5) Feiveson, H.; Mian, Z.; Ramana, M.; von Hippel, F. Managing 775 Spent Fuel from Nuclear Power Reactors. Experience and Lessons from 776 around the World; International Panel on Fissile Materials-IPMF: 777 Princeton, 2014.

778 (6) Konings, R. J.; Wiss, T.; Beně̌, O. Predicting material release 779 during a nuclear reactor accident. Nat. Mater. 2015, 14 (3), 247.

780 (7) U.S. Department of Energy. Yucca Mountain Repository License 781 Application: Safety Analysis Report; U.S. Nuclear Regulatory 782 Commission: 2008.

783 (8) Fuge, R.; Johnson, C. C. Iodine and human health, the role of 784 environmental geochemistry and diet, a review. Appl. Geochem. 2015, $78563,282-302$.

786 (9) Cox, E. M.; Arai, Y. Environmental chemistry and toxicology of 787 iodine. In Advances in Agronomy; Sparks, D. L., Ed.; Academic Press: 788 2014; Vol. 128, Chapter Two, pp 47-96.

789 (10) IAEA. Treatment, Conditioning and Disposal of Iodine-129; 790 Report No. 276; International Atomic Energy Agency: Vienna, 791 Austria, 1987.
(11) Taylor, P.; Lopata, V. J.; Wood, D. D.; Yacyshyn, H. Solubility 792 and stability of inorganic iodides: candidate waste forms for iodine- 793 129. In Environmental Aspects of Stabilization and Solidification of 794 Hazardous and Radioactive Wastes; ASTM International: West 795 Conshohocken, PA, 1989; pp 287-301.

796

(12) Taylor, P. A Review of Methods for Immobilizing Iodine-129 797 Arising from a Nuclear Fuel Recycle Plant, with Emphasis on Waste-Form 798 Chemistry; Atomic Energy of Canada Ltd., Whiteshell Nuclear 799 Research Establishment: 1990; p 50.

(13) Audubert, F.; Carpena, J.; Lacout, J. L.; Tetard, F. Elaboration 801 of an iodine-bearing apatite Iodine diffusion into $\mathrm{a}_{3}\left(\mathrm{VO}_{4}\right)_{2}$ matrix. 802 Solid State Ionics 1997, 95 (1-2), 113-119.

803

(14) Tanabe, H.; Sakuragi, T.; Yamaguchi, K.; Sato, T.; Owada, H. 804 In Development of New Waste Forms to Immobilize Iodine-129 Released 805 from a Spent Fuel Reprocessing Plant; Advances in Science and 806 Technology; Trans Tech Publ: 2010; pp 158-170.

807

(15) Garino, T. J.; Nenoff, T. M.; Krumhansl, J. L.; Rademacher, D. 808 $\mathrm{X}$. Low-temperature sintering Bi-Si-Zn-oxide glasses for use in either 809 glass composite materials or core/shell I-129 waste forms. J. Am. 810 Ceram. Soc. 2011, 94 (8), 2412-2419.

(16) Krumhansl, J. L.; Nenoff, T. M. Hydrotalcite-like layered 812 bismuth-iodine-oxides as waste forms. Appl. Geochem. 2011, 26 (1), 813 $57-64$.

(17) Sava, D. F.; Garino, T. J.; Nenoff, T. M. Iodine confinement 815 into metal-organic frameworks (MOFs): low-temperature sintering 816 glasses to form novel glass composite material (GCM) alternative 817 waste forms. Ind. Eng. Chem. Res. 2012, 51 (2), 614-620. 818

(18) Sava, D. F.; Rodriguez, M. A.; Chapman, K. W.; Chupas, P. J.; 819 Greathouse, J. A.; Crozier, P. S.; Nenoff, T. M. Capture of volatile 820 iodine, a gaseous fission product, by zeolitic imidazolate framework-8. 821 J. Am. Chem. Soc. 2011, 133 (32), 12398-12401.

822

(19) Campayo, L.; Grandjean, A.; Coulon, A.; Delorme, R.; 823 Vantelon, D.; Laurencin, D. Incorporation of iodates into 824 hydroxyapatites: a new approach for the confinement of radioactive 825 iodine. J. Mater. Chem. 2011, 21 (44), 17609-17611. 826

(20) Riley, B. J.; Vienna, J. D.; Strachan, D. M.; McCloy, J. S.; 827 Jerden, J. L., Jr Materials and processes for the effective capture and 828 immobilization of radioiodine: A review. J. Nucl. Mater. 2016, 470, 829 307-326.

830

(21) Riley, B. J.; Schweiger, M. J.; Kim, D.-S.; Lukens, W. W., Jr; 831 Williams, B. D.; Iovin, C.; Rodriguez, C. P.; Overman, N. R.; Bowden, 832 M. E.; Dixon, D. R.; Crum, J. V.; McCloy, J. S.; Kruger, A. A. Iodine 833 solubility in a low-activity waste borosilicate glass at $1000^{\circ} \mathrm{C}$. J. Nucl. 834 Mater. 2014, 452 (1-3), 178-188.

835

(22) Nishi, T.; Noshita, K.; Naitoh, T.; Namekawa, T.; Takahashi, 836 K.; Matsuda, M. Applicability of $\mathrm{V}_{2} \mathrm{O}_{5}-\mathrm{P}_{2} \mathrm{O}_{5}$ glass system for low- 837 temperature vitrification. MRS Online Proc. Libr. 1996, 465, 221.

(23) Yang, J. H.; Shin, J. M.; Park, J. J.; Park, G. Waste Form of 839 Silver Iodide (AgI) with Low-Temperature Sintering Glasses. Sep. Sci. 840 Technol. 2014, 49 (2), 298-304.

(24) Sakuragi, T.; Nishimura, T.; Nasu, Y.; Asano, H.; Hoshino, K.; 842 Iino, K. In Immobilization of Radioactive Iodine Using AgI Vitrification 843 Technique for the TRU Wastes Disposal: Evaluation of Leaching and 844 Surface Properties; MRS Proceedings; Cambridge Univ Press: 2008; p 845 279.

846

(25) Lemesle, T.; Méar, F. O.; Campayo, L.; Pinet, O.; Revel, B.; 847 Montagne, L. Immobilization of radioactive iodine in silver 848 aluminophosphate glasses. J. Hazard. Mater. 2014, 264 (0), 117-126. 849

(26) Maddrell, E.; Gandy, A.; Stennett, M. The durability of iodide 850 sodalite. J. Nucl. Mater. 2014, 449 (1-3), 168-172.

(27) Sheppard, G. P.; Hriljac, J. A.; Maddrell, E. R.; Hyatt, N. C. 852 Silver Zeolites: Iodide occlusion and conversion to sodalite - a 853 potential 129I waste form? MRS Online Proc. Libr. 2006, 932, 36.1. 854

(28) Krumhansl, J. L.; Nenoff, T. M. Hydrotalcite-like layered 855 bismuth-iodine-oxides as waste forms. Appl. Geochem. 2011, 26 (1), 856 $57-64$.

(29) Szente, L.; Fenyvesi, E.; Szejtli, J. Entrapment of iodine with 858 cyclodextrins: Potential application of cyclodextrins in nuclear waste 859 management. Environ. Sci. Technol. 1999, 33 (24), 4495-4498. 860 
861 (30) Wu, S.; Wang, S.; Simonetti, A.; Chen, F.; Albrecht-Schmitt, T. $862 \mathrm{E}$. Incorporation of iodate into uranyl borates and its implication for 863 the immobilization of I-129 in nuclear waste repositories. Radiochim. 864 Acta 2011, 99 (9), 573-579.

865 (31) Stennett, M. C.; Pinnock, I. J.; Hyatt, N. C. Rapid synthesis of $866 \mathrm{~Pb}_{5}\left(\mathrm{VO}_{4}\right)_{3} \mathrm{I}$, for the immobilisation of iodine radioisotopes, by 867 microwave dielectric heating. J. Nucl. Mater. 2011, 414 (3), 352-359. 868 (32) Lu, F. Y.; Dong, Z. L.; Zhang, J. M.; White, T.; Ewing, R. C.; 869 Lian, J. Tailoring the radiation tolerance of vanadate-phosphate 870 fluorapatites by chemical composition control. RSC Adv. 2013, 3 871 (35), 15178-15184.

872 (33) Redfern, S. A. T.; Smith, S. E.; Maddrell, E. R. High873 temperature breakdown of the synthetic iodine analogue of 874 vanadinite, $\mathrm{Pb}_{5}(\mathrm{VO} 4)_{3} \mathrm{I}$ : an apatite-related compound for iodine 875 radioisotope immobilization? Mineral. Mag. 2012, 76 (4), 997-1003. 876 (34) Carpena, J.; Donazzon, B.; Ceraulo, E.; Prene, S. Composite 877 apatitic cement as material to retain cesium and iodine. C. $R$. Acad. 878 Sci., Ser. IIc: Chim. 2001, 4 (4), 301-308.

879 (35) Le Gallet, S.; Campayo, L.; Courtois, E.; Hoffmann, S.; Grin, 880 Y.; Bernard, F.; Bart, F. Spark plasma sintering of iodine-bearing 881 apatite. J. Nucl. Mater. 2010, 400 (3), 251-256.

882 (36) Zhang, M.; Maddrell, E. R.; Abraitis, P. K.; Salje, E. K. H. 883 Impact of leach on lead vanado-iodoapatite $\mathrm{Pb}_{5}\left(\mathrm{VO}_{4}\right)_{3} \mathrm{I}$ : An infrared 884 and Raman spectroscopic study. Mater. Sci. Eng., B 2007, 137 (1-3), 885 149-155.

886 (37) Uno, M.; Shinohara, M.; Kurosaki, K.; Yamanaka, S. Some 887 properties of a lead vanado-iodoapatite $\mathrm{Pb}_{10}\left(\mathrm{VO}_{4}\right)_{6} \mathrm{I}_{2}$. J. Nucl. Mater. 888 2001, 294 (1-2), 119-122.

889 (38) Yao, T.; Lu, F.; Sun, H.; Wang, J.; Ewing, R. C.; Lian, J. Bulk 890 iodoapatite ceramic densified by spark plasma sintering with 891 exceptional thermal stability. J. Am. Ceram. Soc. 2014, 97 (8), $8922409-2412$.

893 (39) Gauthier-Lafaye, F.; Holliger, P.; Blanc, P. L. Natural fission 894 reactors in the Franceville basin, Gabon: A review of the conditions 895 and results of a "critical event" in a geologic system. Geochim. 896 Cosmochim. Acta 1996, 60 (23), 4831-4852.

897 (40) Zhang, Z.; Heath, A.; Valsaraj, K. T.; Ebert, W. L.; Yao, T.; 898 Lian, J.; Wang, J. Mechanism of iodine release from iodoapatite in 899 aqueous solution. RSC Adv. 2018, 8 (8), 3951-3957.

900 (41) White, T. J.; ZhiLi, D. Structural derivation and crystal 901 chemistry of apatites. Acta Crystallogr., Sect. B: Struct. Sci. 2003, 59 902 (1), $1-16$

903 (42) White, T.; Ferraris, C.; Kim, J.; Madhavi, S. Apatite - An 904 adaptive framework structure. In Micro- and Mesoporous Mineral 905 Phases; Ferraris, G., Merlino, S., Eds.; Mineralogical Society of 906 America., 2005; Vol. 57, pp 307-401.

907 (43) Wang, J. Incorporation of iodine into apatite structure: a crystal 908 chemistry approach using Artificial Neural Network. Frontiers in Earth 909 Science 2015, 03, 20.

910 (44) Jiang, C.; Uberuaga, B. P.; Sickafus, K. E.; Nortier, F. M.; 911 Kitten, J. J.; Marks, N. A.; Stanek, C. R. Using "radioparagenesis" to 912 design robust nuclear waste forms. Energy Environ. Sci. 2010, 3 (1), 913 130-135.

914 (45) Jiang, C.; Stanek, C. R.; Marks, N. A.; Sickafus, K. E.; Uberuaga, 915 B. P. Predicting from first principles the chemical evolution of 916 crystalline compounds due to radioactive decay: The case of the 917 transformation of $\mathrm{CsCl}$ to $\mathrm{BaCl}$. Phys. Rev. B: Condens. Matter Mater. 918 Phys. 2009, 79 (13), 132110.

919 (46) Yao, G.; Zhang, Z.; Wang, J. Beta transmutations in apatites 920 with ferric iron as an electron acceptor - implication for nuclear waste 921 form development. Phys. Chem. Chem. Phys. 2017, 19 (37), 2548792225497.

923 (47) Guy, C.; Audubert, F.; Lartigue, J.-E.; Latrille, C.; Advocat, T.; 924 Fillet, $\mathrm{C}$. New conditionings for separated long-lived radionuclides. $C$. 925 R. Phys. 2002, 3 (7), 827-837.

926 (48) Coulon, A.; Grandjean, A.; Laurencin, D.; Jollivet, P.; 927 Rossignol, S.; Campayo, L. Durability testing of an iodate-substituted 928 hydroxyapatite designed for the conditioning of ${ }^{129} \mathrm{I}$. J. Nucl. Mater. 929 2017, 484, 324-331.
(49) Cao, C.; Chong, S.; Thirion, L.; Mauro, J. C.; McCloy, J. S.; 930 Goel, A. Wet chemical synthesis of apatite-based waste forms - A 931 novel room temperature method for the immobilization of radioactive 932 iodine. J. Mater. Chem. A 2017, 5 (27), 14331-14342.

(50) Audubert, F.; Lartigue, J.-E. Iodine immobilization in apatites. 934 Conference Internationale ATALANTE 2000, 2000; Paper P4.13. 935

(51) Suetsugu, Y. Synthesis of lead vanadate iodoapatite utilizing dry 936 mechanochemical process. J. Nucl. Mater. 2014, 454 (1-3), 223-229. 937

(52) Campayo, L.; Audubert, F.; Lartigue, J.-E.; Courtois-Manara, 938 E.; Le Gallet, S.; Bernard, F.; Lemesle, T.; Mear, F. O.; Montagne, L.; 939 Coulon, A.; Laurencin, D.; Grandjean, A.; Rossignol, S. French studies 940 on the development of potential conditioning matrices for iodine 129. 941 MRS Online Proc. Libr. 2015, 1744, 15-20.

(53) Gin, S.; Frugier, P.; Jollivet, P.; Bruguier, F.; Curti, E. New 943 insight into the residual rate of borosilicate glasses: effect of S/V and 944 glass composition. Int. J. Appl. Glass Sci. 2013, 4 (4), 371-382. 945

(54) Muller, I. S.; McKeown, D. A.; Pegg, I. L. Structural behavior of 946 Tc and I ions in nuclear waste glass. Procedia Mater. Sci. 2014, 7, 53- 947 59.

(55) ASTM-C1308-08 Accelerated Leach Test for Diffusive Releases 949 from Solidified Waste and a Computer Program to Model Diffusive, 950 Fractional Leaching from Cylindrical Waste Forms; ASTM Interna- 951 tional: West Conshohocken, PA, 2009; p 14.

952

(56) Côtê, P. L.; Constable, T. W.; Moreira, A. An evaluation of 953 cement-based waste forms using the results of approximately two 954 years of dynamic leaching. Nucl. Chem. Waste Manage. 1987, 7 (2), 955 129-139.

(57) Sani, D.; Moriconi, G.; Fava, G.; Corinaldesi, V. Leaching and 957 mechanical behaviour of concrete manufactured with recycled 958 aggregates. Waste Manage. 2005, 25 (2), 177-182.

(58) Zhu, R.; Ma, G.; Cai, Y.; Chen, Y.; Yang, T.; Duan, B.; Xue, Z. 960 Ceramic tiles with black pigment made from stainless steel plant dust: 961 Physical properties and long-term leaching behavior of heavy metals. 962 J. Air Waste Manage. Assoc. 2016, 66 (4), 402-411.

(59) Côté, P. Contaminant leaching from cement-based waste forms 964 under acidic conditions. Thesis, McMaster University, 1986.

(60) Lasaga, A. C. Kinetic Theory in the Earth Sciences; Princeton 966 University Press: 1998.

(61) Schott, J.; Pokrovsky, O. S.; Oelkers, E. H. The link between 968 mineral dissolution/precipitation kinetics and solution chemistry. Rev. 969 Mineral. Geochem. 2009, 70 (1), 207-258.

(62) Brantley, S. L. Kinetics of mineral dissolution. In Kinetics of 971 Water-Rock Interaction; Springer: 2008; pp 151-210. 972

(63) Frankel, G. S.; Vienna, J. D.; Lian, J.; Scully, J. R.; Gin, S.; Ryan, 973 J. V.; Wang, J.; Kim, S. H.; Windl, W.; Du, J. A comparative review of 974 the aqueous corrosion of glasses, crystalline ceramics, and metals. npj 975 Materials Degradation 2018, 2 (1), 15.

(64) Eyring, H. The activated complex and the absolute rate of 977 chemical reactions. Chem. Rev. 1935, 17 (1), 65-77. 978

(65) Eyring, H. The activated complex in chemical reactions. J. 979 Chem. Phys. 1935, 3 (2), 107-115.

980

(66) Thomsen, J. S. Logical relations among the principles of 981 statistical mechanics and thermodynamics. Phys. Rev. 1953, 91 (5), 982 $1263-1266$

(67) Klein, M. J. Principle of detailed balance. Phys. Rev. 1955, 97984 (6), 1446-1447.

(68) Dove, P. M.; Han, N. Kinetics of mineral dissolution and 986 growth as reciprocal microscopic surface processes across chemical 987 driving force. AIP Conf. Proc. 2007, 916 (1), 215-234.

(69) Cama, J.; Ganor, J.; Ayora, C.; Lasaga, C. A. Smectite 989 dissolution kinetics at $80^{\circ} \mathrm{C}$ and $\mathrm{pH}$ 8.8. Geochim. Cosmochim. Acta 990 2000, 64 (15), 2701-2717.

(70) Guidry, M. W.; Mackenzie, F. T. Experimental study of igneous 992 and sedimentary apatite dissolution: Control of $\mathrm{pH}$, distance from 993 equilibrium, and temperature on dissolution rates. Geochim. 994 Cosmochim. Acta 2003, 67 (16), 2949-2963.

(71) Hellmann, R. Tisserand, D. Dissolution kinetics as a function 996 of the Gibbs free energy of reaction: An experimental study based on 997 albite feldspar. Geochim. Cosmochim. Acta 2006, 70 (2), 364-383. 998 
999 (72) Gustafsson, J. P. Visual MINTEQ 3.0 user guide; KTH, 1000 Department of Land and Water Recources: Stockholm, Sweden, 2011. 1001 (73) Fleet, M. E. Carbonated Hydroxyapatite: Materials, Synthesis, 1002 and Applications; CRC Press: 2014.

1003 (74) Kresse, G.; Marsman, M.; Furthmuller, J. Vienna ab-initio 1004 simulation package, VASP the Guide; Universitat Wein: Wien, Austria, 1005 2014; p 209.

1006 (75) Blöchl, P. E. Projector augmented-wave method. Phys. Rev. B: 1007 Condens. Matter Mater. Phys. 1994, 50 (24), 17953-17979.

1008 (76) Perdew, J. P.; Wang, Y. Accurate and simple analytic 1009 representation of the electron-gas correlation energy. Phys. Rev. B: 1010 Condens. Matter Mater. Phys. 1992, 45 (23), 13244-13249.

1011 (77) Perdew, J. P.; Chevary, J. A.; Vosko, S. H.; Jackson, K. A.; 1012 Pederson, M. R.; Singh, D. J.; Fiolhais, C. Atoms, molecules, solids, 1013 and surfaces: Applications of the generalized gradient approximation 1014 for exchange and correlation. Phys. Rev. B: Condens. Matter Mater. 1015 Phys. 1992, 46 (11), 6671-6687.

1016 (78) Perdew, J. P.; Wang, Y. Accurate and simple density functional 1017 for the electronic exchange energy: Generalized gradient approx1018 imation. Phys. Rev. B: Condens. Matter Mater. Phys. 1986, 33 (12), 1019 8800-8802.

1020 (79) Sheppard, D.; Terrell, R.; Henkelman, G. Optimization 1021 methods for finding minimum energy paths. J. Chem. Phys. 2008, 1022128 (13), 134106.

1023 (80) Harouiya, N.; Chaïrat, C.; Köhler, S. J.; Gout, R.; Oelkers, E. H. 1024 The dissolution kinetics and apparent solubility of natural apatite in 1025 closed reactors at temperatures from 5 to $50 \mathrm{C}$ and $\mathrm{pH}$ from 1 to 6 . 1026 Chem. Geol. 2007, 244 (3-4), 554-568.

1027 (81) Audubert, F.; Savariault, J.-M.; Lacout, J.-L. Pentalead 1028 tris(vanadate) iodide, a defect vanadinite-type compound. Acta 1029 Crystallogr., Sect. C: Cryst. Struct. Commun. 1999, 55 (3), 271-273. 1030 (82) Hughes, J. M.; Cameron, M.; Crowley, K. D. Structural 1031 variations in natural $\mathrm{F}, \mathrm{OH}$, and $\mathrm{Cl}$ apatites. Am. Mineral. 1989, 74 1032 (7-8), 870-876.

1033 (83) Köhler, S. J.; Harouiya, N.; Chärat, C.; Oelkers, E. H. 1034 Experimental studies of REE fractionation during water-mineral 1035 interactions: REE release rates during apatite dissolution from $\mathrm{pH} 2.8$ 1036 to 9.2. Chem. Geol. 2005, 222 (3-4), 168-182.

1037 (84) Chaïrat, C.; Schott, J.; Oelkers, E. H.; Lartigue, J.-E.; Harouiya, 1038 N. Kinetics and mechanism of natural fluorapatite dissolution at $25 \mathrm{C}$ 1039 and $\mathrm{pH}$ from 3 to 12. Geochim. Cosmochim. Acta 2007, 71 (24), 1040 5901-5912. 